\title{
Malignant gastrointestinal stromal tumor presenting with hemoperitoneum in puerperium: report of a case with review of the literature
}

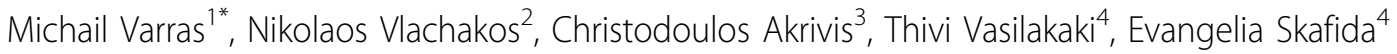

\begin{abstract}
Background: Gastrointestinal stromal tumors (GISTs) are mesenchymal tumors that develop in the wall of the gastrointestinal tract and their diagnosis during pregnancy or puerperium is extremely rare.

Case: A 28-year old patient presented with acute abdomen due to hemoperitoneum from a large mass arising of the small intestine with distended vessels on its top and a ruptured superficial vessel bleeding into the peritoneal cavity. The patient was at the tenth postpartum day of her first pregnancy. The preoperative diagnosis was a possible ovarian or uterine mass. After an emergency exploratory laparotomy a segmental bowel resection was performed, removing the tumor with a part of $3-\mathrm{cm}$ of the small intestine. Histology revealed GIST with maximum diameter of $13 \mathrm{~cm}$ and mitotic rates more than 5 mitoses per 50 high power fields with some atypical forms, indicating a high risk malignancy. Immunohistochemical staining of the tumor tissue demonstrated strongly positive reactivity to CD 117 (c-kit) and CD34 in almost all the tumor cells. The patient was treated with oral imatinib mesylate (Gleevec) $400 \mathrm{mg}$ daily for one year. Three years after surgery, the patient was alive without evidence of metastases or local recurrence.

Conclusion: Considering that only few patients with gastrointestinal stromal tumors have been reported in the obstetrical and gynecological literature, the awareness of such an entity by the obstetricians-gynecologists is necessary in order to facilitate coordinated approach with the general surgeons and oncologists for the optimal care of the patients.
\end{abstract}

\section{Introduction}

Gastrointestinal stromal tumors (GISTs) are uncommon tumors that develop in the wall of the gastrointestinal tract and usually present in the fifth to seventh decade of life $[1,2]$. They account for approximately $0.1 \%$ to $3 \%$ of all gastrointestinal neoplasms, with an incidence of 1-20 per million and up to $30 \%$ of these are considered malignant $[1,3,4]$. The term gastrointestinal sromal tumor, first used by Mazur and Clark in 1983, encompasses a heterogeneous group of nonepithelial neoplasms composed of spindle or epithelioid cells, which display a range of differentiation [5]. Given the age distribution of occurrence, a diagnosis of gastrointestinal

\footnotetext{
* Correspondence: mnvarras@otenet.gr

'Department of Obstetrics and Gynecology, 'Tzaneio' General State Hospital, Piraeus, Greece

Full list of author information is available at the end of the article
}

stromal tumor during pregnancy [6-8] or puerperium is very uncommon.

We hereby describe our experience of the case of a GIST discovered during the puerperium, in a 28 -year old patient presented with acute abdomen due to spontaneous rupture of a superficial tumor vessel, an extremely rare complication and review the current literature.

\section{Case Report}

A 28-year-old woman was brought to the emergency department of our hospital with severe lower abdominal pain, which became generalized and intolerable. The patient was at the tenth postpartum day of her first pregnancy and had no remarkable medical or surgical history. Also, the patient had no history of an irregular menstruation cycle. As the patient mentioned, during her pregnancy the uterus was considered too large for her gestational age and on routine ultrasounds a 
subserosal fibroid was suspected. The crown rump length was in accordance with her last menstrual period and the fetal growth was within the normal limits as well, according to the patient's information. She had a normal delivery at term at a Private Maternity Hospital of Athens. The patient denied any medical history of gastrointestinal symptoms such as emesis, melaena, abdominal pain or ileus during her pregnancy. At presentation, she was nauseous and had vomited a number of times. Physical examination revealed a pale, moderately obese young woman with a heart rate of 104 beats per minute, blood pressure $130 / 70 \mathrm{mmHg}$ and temperature $36^{\circ} \mathrm{C}$. Her abdomen was extensively distended, markedly tender with moderate spasm and rebound tenderness in both iliac fossae. Peristaltic sounds were diminished. Her blood count demonstrated a haemoglobin concentration of $9.4 \mathrm{~g} / \mathrm{dl}$, haematocrit $31 \%$, white blood count 18,000 cells/ml with $89.7 \%$ polymorphonuclears and platelets $352,000 / \mu l$. Clotting time, bleeding time, serum liver enzymes and kidney function tests were within normal limits. L.D.H. was 297 U/l (normal rates 100-240 U/l). An abdominal ultrasound examination revealed a large mass measuring $12.85 \times 10.52-\mathrm{cm}$ with mixed echogenicity, occupying all the pelvis and extending above the pubic symphysis and from the midline to the left (Figures 1-2). Two cystic areas within the mass measuring approximately $4.30 \times 4.97-\mathrm{cm}$ and 3.54 $\times 3.66-\mathrm{cm}$ were found (Figures 2). The ovaries were not visualized. Free fluid was present at the Morisson's space and the cul-de-sac with low levels of echogenic debris. Chest X-ray examination was negative. Under

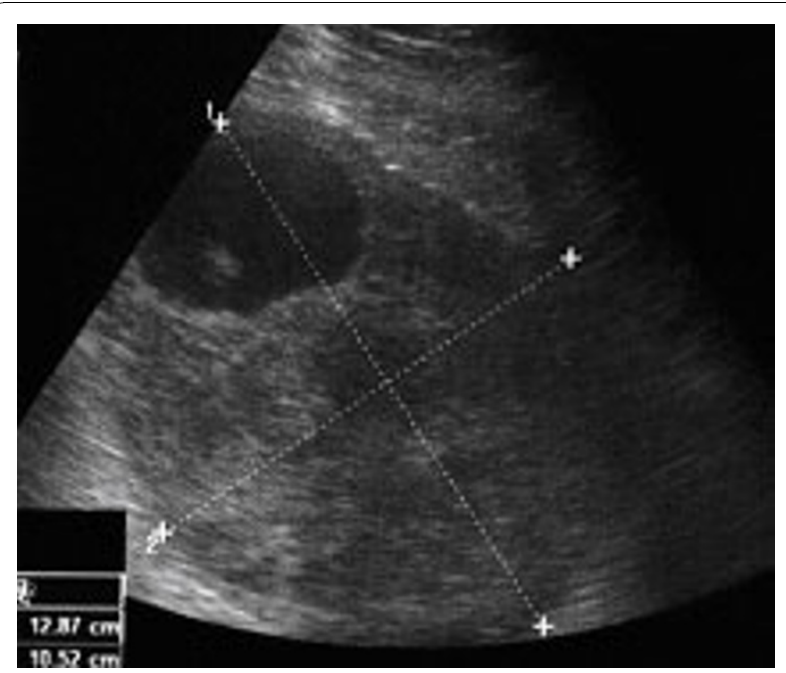

Figure 1 Abdominal ultrasonography revealed a large mass measuring $12.85 \times 10.52-\mathrm{cm}$ with mixed echogenicity, occupying the pelvis and extending above the pubic symphysis; two cystic areas within the mass measuring approximately $4.30 \times 4.97-\mathrm{cm}$ and $3.54 \times 3.66-\mathrm{cm}$ are noted

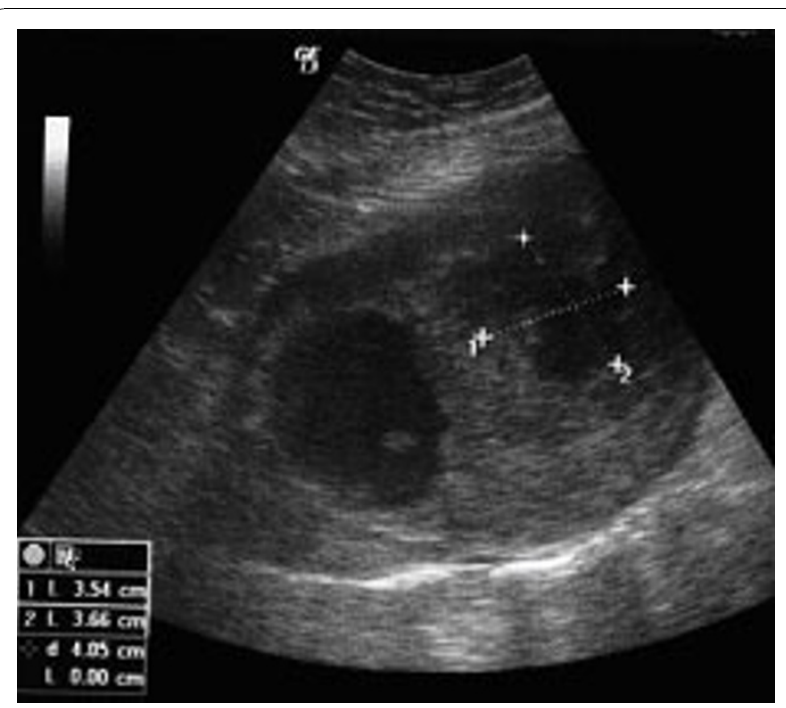

Figure 2 Abdominal ultrasonography revealed a large mass measuring $12.85 \times 10.52-\mathrm{cm}$ with mixed echogenicity, occupying the pelvis and extending above the pubic symphysis; two cystic areas within the mass measuring approximately $4.30 \times 4.97-\mathrm{cm}$ and $3.54 \times 3.66-\mathrm{cm}$ are noted

the diagnosis of hemoperitoneum from a possible ovarian or uterine mass, an immediate exploratory laparotomy was performed. At laparotomy with a vertical, midline infra-umbilical incision bloodstained fluid and blood clots in the peritoneal cavity were found. Further exploration revealed a large mass arising from the small intestine and growing exophytically out into the peritoneal cavity (Figure 3). On the top of the mass, distended vessels were observed and a ruptured superficial vessel was actively bleeding into the abdominal cavity; no other bleeding was indentified. Free fluid was obtained for cytology. One liter of fluid and blood clots were evacuated. A segmental bowel resection was performed, removing the tumor with a part of $3-\mathrm{cm}$ of the small intestine (Figure 4). The abdominal cavity was irrigated and carefully inspected; the omentum, the ovaries and the uterus had normal macroscopic appearance and no visible findings suspicious of malignancy were found. The patient made a good recovery post-operatively.

Grossly, the surgical specimen of the small intestine showed a well-circumscribed tumor measuring $13 \times 10$ $\times 9-\mathrm{cm}$ in size and located $3-\mathrm{cm}$ from the nearest surgical martin (Figure 5). The external surface of the tumor showed pronounced appearance of its vessels. Part of the tumor was covered by the instinal musosa. The cut surface demonstrated whitish-gray solid parenchyma, with two cystic areas of degeneration with hemorrhagic fluid; the largest cyst measured 5-cm in its maximum diameter. The solid portion was soft in composition. Microscopically, the neoplastic cells were mainly 


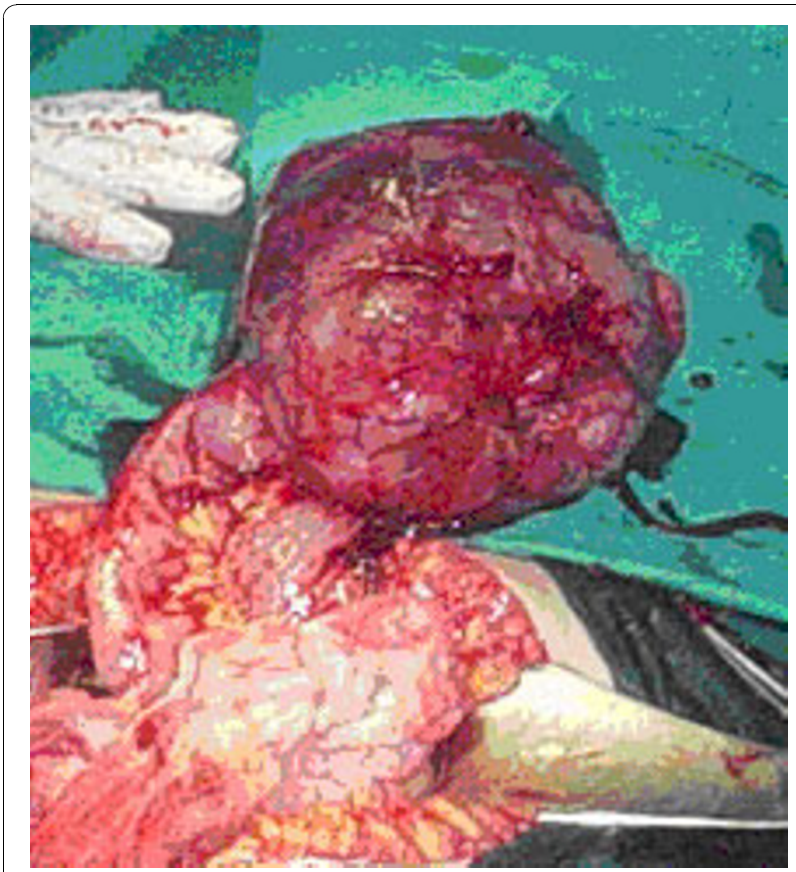

Figure 3 Exploration of the peritoneal cavity revealed a large mass arising from the small intestine and growing exophytically out into the peritoneal cavity. On the top of the mass, distended vessels were observed and a ruptured superficial vessel was actively bleeding into the abdominal cavity.

spindle-shaped or partly epithelioid (Figures 6,7 ). The mitotic rate was more than 5 mitoses per 50 HPFs (high power fields) with some atypical forms. The neoplastic stroma showed an important vascular component. There were some areas with necrosis, hemorrhage, and cystic degeneration. Immunohistochemical staining of the tumor tissue demonstrated strongly positive reactivity to CD 117 (c-kit) (Figure 8) and CD34 (Figure 9) in

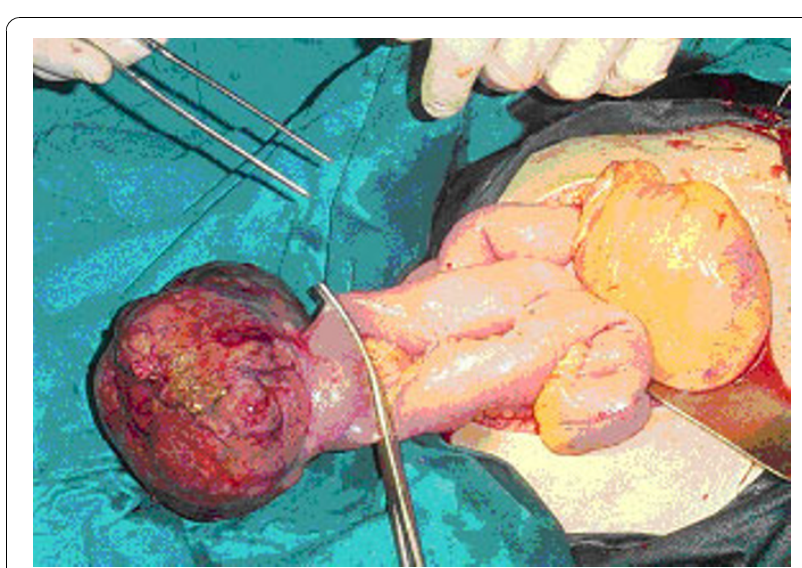

Figure 4 Demonstration of the resection of segmental bowel; the tumor was removed with a part of $3-\mathrm{cm}$ of the small intestine.

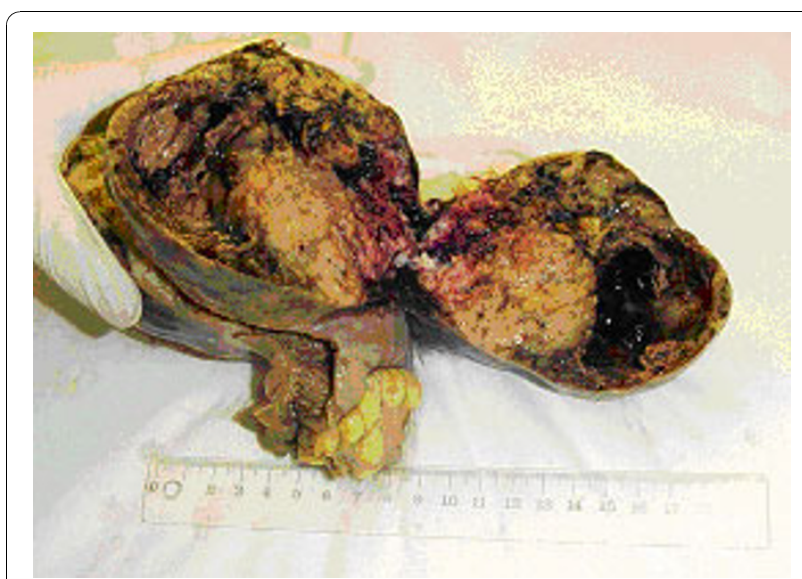

Figure 5 The surgical specimen of the small intestine was a well-circumscribed tumor measuring $13 \times 10 \times 9-\mathrm{cm}$ in size and located $3-\mathrm{cm}$ from the nearest surgical margin. The cut surface demonstrated whitish-gray solid parenchyma, with two cystic areas of degeneration with hemorrhagic fluid; the solid portion was soft in composition.

almost all the tumor cells, whereas a small percentage of the neoplastic cells was positive for $\alpha$-smoth muscle actin. The immunostaining was negative for desmin, S-100 protein, and cytokeratins of high and low molecular weight. Cell proliferation by Ki-67 immunostaining was low. The tumor was diagnosed as a primary malignant gastrointestinal stromal tumor with high risk. The surgical margins of the intestinal specimen were negative for tumor cells. Cytologic examination of the peritoneal fluid obtained intraoperatively was negative for malignancy.

The patient's postoperative course was uneventful and she was treated with oral imatinib mesylate (Gleevec) $400 \mathrm{mg}$ daily for one year. Three years after surgery for

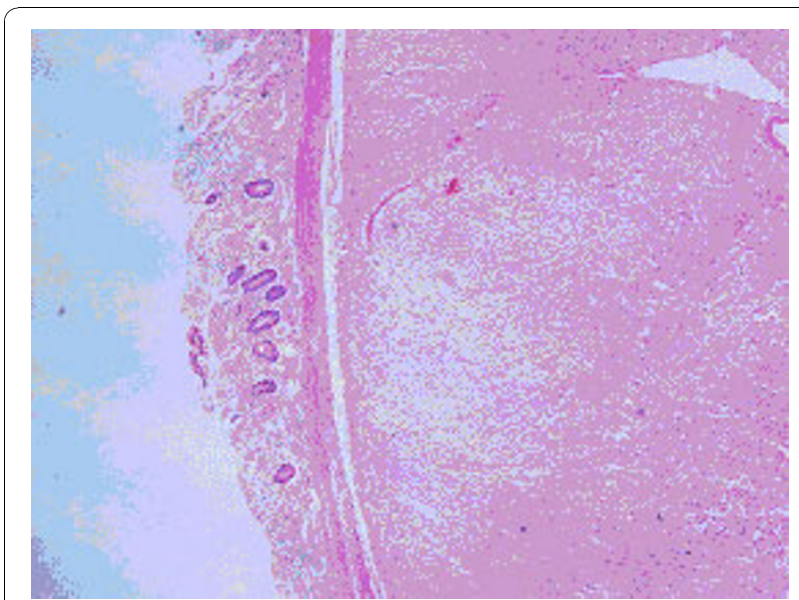

Figure 6 Microscopically, the neoplasticcells were mainly spindle-shaped or partly epithelioid. Figures 13 : H\&E $\times 40$; Figure 14: H\&E $\times 100$ 


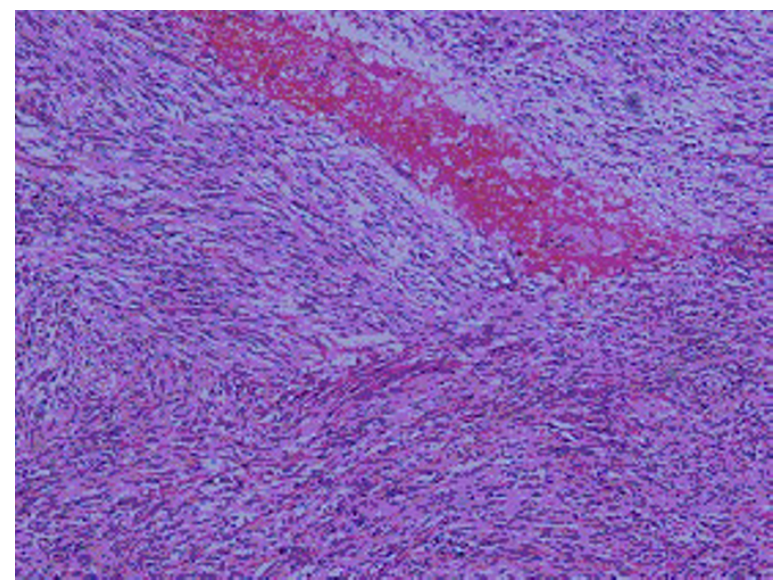

Figure 7 Microscopically, the neoplasticcells were mainly spindle-shaped or partly epithelioid. Figures 13: H\&E $\times 40$; Figure 14: H\&E $\times 100$.

the primary gastrointestinal stromal tumor, the patient is alive. A recent CT scan of the upper and lower abdomen was negative for local recurrences of the disease or secondary metastases.

\section{Discussion}

GISTs occur anywhere in the intestine, with the most common site being the stomach (50-60\%), followed by the small intestine (20-30\%), large bowel (10\%), the oesophagus (5\%), and only $5 \%$ elsewhere in the abdominal cavity such as in the mesentery, omentum or retroperitoneum $[2,9]$.

GISTs may be detected during a gastroscopy as submucosal tumors or occasionally as incidental radiologic findings. The symptomatic GISTs of the esophagus typically present with dysphagia. Gastric and small intestinal GISTs

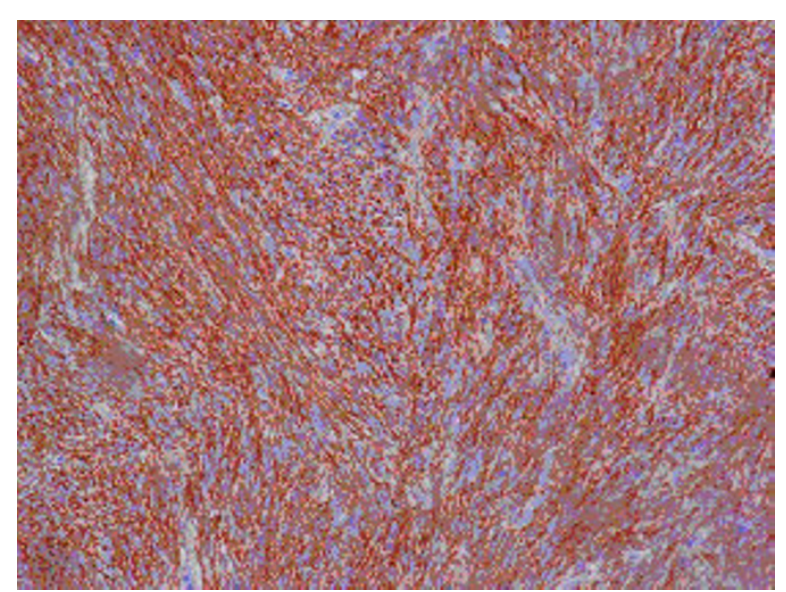

Figure 8 Immunohistochemical staining of the tumor tissue demonstrated strongly positive reactivity to CD 117 (c-kit) in almost all the tumor cells.

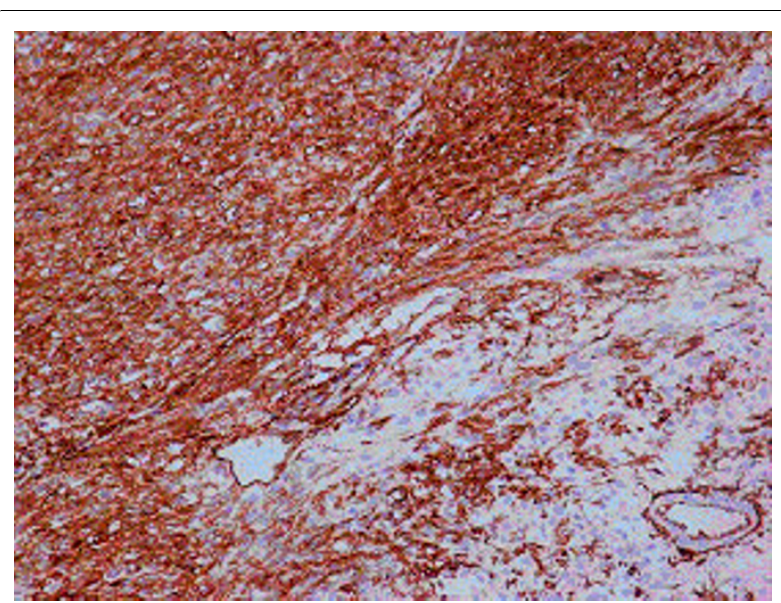

Figure 9 Immunohistochemical staining of the tumor tissue demonstrated strongly positive reactivity to CD34 in almost all the tumor cells.

often present with vague symptoms, but sometimes they cause upper gastrointestinal bleeding. Colorectal GISTs may manifest with lower gastrointestinal bleeding, colonic perforation, pain, obstruction or combination [4,10,11]. Also, fever or liver metastasis have described as first symptoms [12]. Rarely, they can present with intraperitoneal bleeding secondary to surface tumor ulteration $[9,10]$. Our patient presented clinically with pelvic pain and a pelvic mass diagnosed ultasonographically showing adequate fluid in the abdominal and pelvic cavities. The preoperative diagnosis was consistent with acute abdomen from a possible ovarian or uterine tumor. The ultrasonographic findings of GISTs are non-characteristic and therefore a preoperative presumptive diagnosis based on imaging is virtually impossible [9]. In our patient, during the operation, on the top of the mass a ruptured superficial vessel was found to bleed actively into the abdominal cavity and no other bleeding was indentified. It seems that the hemoperitoneum resulting from a solid mass is secondary to passive blood congestion, subsequent rupture of a superficial tumoral vessel and spontaneous internal bleeding [13]. The postpartum hyperfibrinolysis might play a role for the bleeding of the mass. A diagnosis of GIST during pregnancy is very uncommon [6-8]. Those few cases reported were symptomatic and found in the second half of the pregnancy, leading to an emergency cesarean section in one case due to fetal distress during laparotomy [6,7]. The delay in diagnosis of GISTs during pregnancy is normally due to the clinicians' reluctance to request diagnostic examinations during pregnancy and to the non-specific symptoms of the disease [8]. Our patient had a normal delivery at term at a Private Maternity Hospital of Athens, because no obstruction of labor had occurred obviously. Possibly, the large mass arising from the small intestine and growing exophytically out into the peritoneal cavity 
was removed outside the pelvis by the pregnant uterus. For the same reason the patient might have tolerated the high pressure during labor and the tumor did not stared bleeding during labor.

Macroscopically, GISTs are usually grey-white in appearance. They arise in the muscularis propria, and can grow either exophytically out into the peritoneum, or endophytically into the lumen of the gut [2]. Microscopically, GISTs are well-circumscribed smooth lobulated, uncapsulated tumours. They are composed of spindle cells or epithelioid cells, or a mixture of both, and may show areas of cystic degeneration, necrosis or focal hemorrhage [Sanjay et al 2004]. The hypothesis that GISTs originate from the primitive stem cell that can differentiate toward the interstitial cells of Cajal, has been advocated. Interstitial cells of Cajal are autonomous nerve-related GI pacemaker cells that regulate intestinal motility and are immunoreactive for a specific immunostain (CD117) of a c-kit proto-oncogene protein (KIT), which encodes for a transmembrane tyrosinekinase receptor [14-18]. Mutations of c-kit protooncogen seem to produce overexpression of the KIT protein, which is responsible for the pathogenesis of GISTs [2]. Also, GISTs are often positive for CD34 and variably positive for smooth muscle actin [19]. Mesenchymal tumors of the uterus and ovaries are thought to rarely express c-kit, but if they do, the staining is usually focal, with fewer than $5 \%$ of cells been positive $[9,20,12]$. The final diagnosis of our patient was established based on the intestinal origin of the neoplasm and its histopathologic and immunohistochemical findings. The immunohistochemical analysis showed positive reactivity to the c-kit gene, CD34, a-smooth muscle actin, but no reactivity to $S-100$ protein.

Management depends on complete surgical resection, incomplete resection being associated with a median survival of less than 20 months. The wide margins of resection are not necessary as there is minimal local invasion and similarly lymphadenectomy is not routinely necessary as local lymph nodes are not usually affected [2]. Various systemic chemotherapeutic regimes, radiation and intraperitoneal chemotherapy has been used with little success [9]. However, Joensuu et al reported the first use of STI-571 (imatinib mesylate, Gleevec) in a case of recurrent metastatic GIST that failed extensive surgical therapy and chemotherapy [21]. The dramatic response in their case was documented both clinically and histologically. They also documented a marked decrease in tumor activity by 18FDG-PET scanning. Shortly after reporting the case, confirmatory data were published [22,23].

Prognostic factors indicating the possible malignant potential of gastrointestinal tumors are mitotic activity (>5 mitotic figures per $50 \times$ high power field) and tumor size $(>5-\mathrm{cm})$. Tumors that have the c-kit exon 11 mutation are also at greater risk [2]. Tumor rupture before or during surgery has also been linked to poor prognosis $[9,4,24]$. Factors as mucosal invasion and tumor necrosis have found to be related to increased risk of aggressive behavior, but their clinical value remains uncertain [24]. The spread pattern of gastrointestinal tumors with malignant potential shows predilection for liver metastasis and peritoneal dissemination. Therefore, the presence of hepatic or peritoneal lesions on presentation usually represents a sign of poor prognosis $[4,9]$. In addition, incomplete surgical resection is associated with a reduced survival [2]. Chemotherapy with imatinib (Gleevec, Novartis, Switzerland) was perfomed in our patient due to the large tumor size $(>5-\mathrm{cm})$, and mitotic activity $(>5 / 50 \mathrm{HPF})$. Reccurrence or metastasis after complete surgical resection may occur in more than two thirds of all gastrointestinal stromal tumors. Recurrence is usually local or peritoneal and often associated with liver metastases. Most recurrences occur within 2 years of the original tumor, although intervals of up to 10 years have been reported (2). In our case, three years after surgery, the patient was alive and the recent $\mathrm{CT}$ scan of the upper and lower abdomen showed no local recurrences of the disease or secondary metastases. Because of limited experience of GISTs diagnosed during pregnancy, no reference is made to the possibility of metastatic disease in the fetus or the developing of GIST in utero [6].

\section{Conclusions}

Since only few patients with gastrointestinal stromal tumors have been reported in the obstetrical and gynecological literature $[6,7,12,8,25-31]$, the awareness of such an entity by the obstetricians-gynecologists is necessary in order to include this in the differential diagnosis of minor gastrointestinal discomfort during pregnancy and in addition to facilitate coordinated approach with the general surgeons and oncologists for the optimal care of the patients. Complete surgical resection and immediate therapy with imatinib are associated with better survival of patients with such refractory tumors for radiotherapy and conventional chemotherapy. For GISTs diagnosed during pregnancy no reference is made to the possibility of metastatic disease in the fetus or the developing of GIST in utero [6]. For pregnant patients with suspicious tumor findings on ultrasonography, the ultrasound examination should determine the origin of the mass and its location, size and internal structure. For ovarian masses, color Doppler imaging should also be performed. Pelvic MRI with gadolinium injection can be performed after the first trimester to remove any doubt or to provide additional information if the ultrasound examination is not sufficient 
or as a tool for the assessment of cancer. Pelvic CT scanning is not indicated during pregnancy. Surgery should be immediate considered in cases of acute symptoms or suspicious tumors for malignancy [32]. The best predictor of whether a uterine leiomyoma cause problem during pregnancy is its location. Submucosal leiomyomas interfere with the implantation of the placenta, subserosal feiomyomas present with infarction, while leiomyomas in the cervix or at lower uterine segment may cause obstruction of the labor. Rarely, large submucosal nonpedunculated uterine leiomyoma can interfere with puerpurium by obstructing the passage of lochia and leading to haematometra and uterine atony [33].

\section{Consent}

Written informed consent was obtained from the patient for publication of this case report and accompanying images. A copy of the written consent is available for review by the Editor-in-Chief of this journal.

\section{Author details}

'Department of Obstetrics and Gynecology, 'Tzaneio' General State Hospital, Piraeus, Greece. ${ }^{2}$ Department of General Surgery, Tzaneio General State Hospital, Piraeus, Greece. ${ }^{3}$ Department of Obstetrics and Gynecology, 'G. Chatzikosta' General State Hospital, loannina, Greece. ${ }^{4}$ Department of Pathology, 'Tzaneio' General State Hospital, Piraeus, Greece.

\section{Authors' contributions}

MV was the principal investigator and responsible for the original conception and design, has taken part in the operation, edited the manuscript, supervised the whole attempt and was responsible as well for images, correction, revision, and approval of the final version. NV has operated, was clinically responsible for patient's care and edited the manuscript. ChA has edited the manuscript. ThV was responsible for the histology consulting and pathology examination and has edited the manuscript. ES has diagnosed and edited the manuscript. All authors read and approved the final manuscript.

\section{Competing interests}

The authors declare that they have no competing interests.

Received: 31 March 2010 Accepted: 7 November 2010

Published: 7 November 2010

\section{References}

1. Crosby JA, Catton CN, Davis A, Couture J, O'Sullivan B, Kandel R, Swallow CJ: Malignant gastrointestinal stromal tumors of the small intestine: Review of 50 cases from a prospective database. Annals Surg Oncol 2001, 8:50-59.

2. Towu E, Stanton M: Gastrointestinal stromal tumor presenting with severe bleeding: a review of the molecular biology. Pediatr Surg Int 2006, 22:462-464.

3. Lewis JJ, Brennan MF: Soft tissue sarcomas. Curr Prob/ Surg 1996, 33:817-872.

4. Miettinen M, Virolainen M, Rikala MS: Gastrointestinal stromal tumors value of CD34 antigen in their identification and separation from true leiomyomas and schwannomas. Am J Surg Pathol 1995, 19:207-216.

5. Mazur MT, Clark HB: Gastric stromal tumors: Reappraisal of histogenesis. Am J Surg Pathol 1983, 7:507-519

6. Scherjon S, Lam WF, Gelderblom H, Jansen FW: Gastrointestinal stomal tumor in pregnancy: a case report. Case Rep Med 2009, article ID 456402

7. Valente PT, Fine BA, Parra C, Schroeder B: Gastric stromal tumor with peritoneal nodules in pregnancy: tumor spread or rare variant of diffuse leiomyomatosis. Gynecol Oncol 1996, 63:392-397.
8. Lanzafame S, Mimutolo V, Caltabiano R, Minutolo O, Marino B, Gagliano G, D'Asta S: About a case of GIST occuring during pregnancy with immunohistochemical expression of epidermal growth factor receptor and pregesterone receptor. Pathology Research Practice 2006, 202:119-123.

9. Zighelboim I, Gwendolyn H, Kunda A, Gutierrez C, Edwards C: Gastrointestinal stromal tumor presenting as a pelvic mass. Gynecol Oncol 2003, 91:630-635.

10. Cheon YK, Jung IS, Cho YD, Kim JO, Lee JS, Lee MS, Kim JH, Hur KY, Jin SY, Shim CS: A spontaneously ruptured gastric stromal tumor with cystic degeneration presenting with hemoperitoneum: a case report. $J$ Korean Med Sci 2003, 18:751-755.

11. Ueyama T, Guo KJ, Hashimoto H, Daimaru Y, Enjoji M: A clinicopathologic and immunohistochemical study of gastrointestinal stromal tumors. Cancer 1992, 69:947-955.

12. Wingen CBM, Pauwels PAA, Debiec-Rychter $M$, van Gemert WG, Vos MC: Uterine gastrointestinal stromal tumor (GIST). Gynecol Oncol 2005, 97:970-972.

13. Varras M, Tsikini A, Polyzos D, Samara Ch, Akrivis Ch: Internal hemorrhage caused by a twisted malignant ovarian dysgerminoma: ultrasonographic findings of a rare case and review of the literature. Clin Exp Obstet Gynecol 2004, 31:73-8.

14. Hirota S, Isozaki K, Moriyama $Y$, Hashimoto K, Nishida T, Ishiguro S, Kawano K, Hanada M, Kurata A, Takeda M, Muhammad TG: Gain-offunction mutations of c-kit in human gastrointestinal stromal tumors. Science 1998, 279:577-580.

15. Thomsen L, Robinson TL, Lee JC, Farraway LA, Hughes MJ, Andrews DW Huizinga JD: Interstitial cells of Cajal generate a rhythmic pacemaker current. Nat Med 1998, 4:848-851.

16. Kindblom LG, Remotti HE, Aldenborg F, Meis-Kindblom JM: Gastrointestitial pacemaker cell tumor (GIPACT). Am J Pathol 1998, 152:1259-1269.

17. Kitabayashi K, Seki T, Kishimoto K, Saitoh H, Ueno K, Kita I, Takashima S, Kurose N, Nojima T: A spontaneously ruptured gastric stromal tumor presenting as generalized peritonitis: report of a case. Surg Today 2001, 31:350-354.

18. Maeda H, Yamagata A, Nishikawa S, Yoshinaga K, Kobayashi S, Nishi K, Nishikawa S: Requirment of c-kit for development of intestinal pacemaker system. Development 1992, 116:369-375.

19. Takano M, Saito K, Kita T, Furuya K, Aida S, Kikuchi Y: Preoperative needle biopsy and immunohistochemical analysis for gastrointestinal stromal tumor of the rectum mimicking vaginal leiomyoma. Inter J Gynecol Cancer 2006, 16:884-943.

20. Klein WM, Kurman RJ: Lack of expression of c-kit protein (CD117) in mesenchymal tumors of the uterus and ovary. Int J Gynaecol Pathol 2003, 22:181-184.

21. Joensuu H, Roberts PJ, Sarlomo-Rikala M, Andersson LC, Tervahartial P, Tuveson D, Silberman S, Capdeville R, Dimitrijevic S, Druker B, Demetri GD: Effect of the tyrosine kinase inhibitor STI571 in a patient with a metastatic gastrointestinal stromal tumor. N Engl J Med 2001, 344:1052-1056

22. Van Oosterom AT, Judson I, Verweij J, Stroobants S, Donato di Paola E, Dimitrijevic S, Martens M, Webb A, Sciot R, Van Glabbekc M, Silberman S, Nielsen OS: Safety and efficancy of Imatinib (STI571) in metastatic gastrointestinal stromal tumours: A phase I study. Lancet 2001, 358:1421-1423.

23. Demetri $G D$, von Mehren $M$, Blanke $C D$, Van den Abbeele $A D$, Eisenberg $B$, Roberts PJ, Heinrich MC, Tuveson DA, Singer S, Janicek M, Fletcher JA, Silverman SG, Silberman SL, Capdeville R, Kiese B, Peng B, Dimitrijevic S, Druker BJ, Corless C, Fletcher CD, Joensuu H: Efficacy and safety of imatinib mesylate in advanced gastrointestinal stromal tumors. $N$ Engl J Med 2002, 347:462-463.

24. Nigri GR, Dente M, Valabrega S, Aurello P, D'Angelo F, Montrone G, Ercolani G, Ramacciato G: Gastrointestinal stromal tumor of the anal canal: an unusual presentation. World J Surg Oncol 2007, 5:20.

25. Hsu S, Chen SS: Gastrointestinal stromal tumors presenting as gynecological tumors. Eur J Obstet Gynecol 2006, 125:139-145.

26. Nasu K, Ueda T, Kai S, Anai H, Kimura Y, Yokoyama S, Miyakawa : Gastrointestinal stromal tumor arising in the rectovaginal septum. Int J Gynecol Cancer 2004, 14(2):373-7.

27. Powell $J$, Kotwall CA, Wright BD, Temple RH Jr, Ross SC, White WC: Gastrointestinal stromal tumor mimicking ovarian neoplasia. J Pelvic Surg 2002, 8:117-9. 
28. Erkanli S, Kayaselcuk F, Torer N, Bolat F, Tarim E, Simsek E, Kuscu E: Gastrointestinal stromal tumors presenting as pelvic masses: report of two cases. Eur J Gynaecol Oncol 2006, 27:101-103.

29. Belics Z, Csapo Z, Szabo I, Papay J, Szabo J, Papp Z: Large gastrointestinal stromal tumor presenting as an ovarian tumor. A case report. J Reprod Med 2003, 48:655-8.

30. Morimura Y, Yamashita N, Koyama N, Ohzeki T, Takayama T, Fujimori K, Sato A: Gastrointestinal stromal tumor mimicking gynecological disease. Fukushima J Med Sci 2006, 52:21-28.

31. Renaud MC, Plante M, Roy M: Metastatic gastrointestinal tract cancer presenting as ovarian carcinoma. J Obstet Gynecol Can 2003, 25:819-824.

32. Marret $\mathrm{H}$, Lhommé $\mathrm{C}$, Lecuru F, Canis $\mathrm{M}$, Lévèque J, Golfier F, Morice Ph: Guidelines for the management of ovarian cancer during pregnancy. Eur J Obstet Gynecol Reprod Biol 2010, 149:18-21.

33. Akrivis Ch, Varras M, Bellou A, Kitsiou E, Stefanaki S, Antoniou N: Primary postpartum haemorrhage due to a large submocosal nonpedunculated uterine leiomyoma: a case report and review of the literature. Clin Exp Obstet Gynecol 2003, 30:156-158.

doi:10.1186/1477-7819-8-95

Cite this article as: Varras et al:: Malignant gastrointestinal stromal tumor presenting with hemoperitoneum in puerperium: report of a case with review of the literature. World Journal of Surgical Oncology 2010 8:95.

\section{Submit your next manuscript to BioMed Central} and take full advantage of:

- Convenient online submission

- Thorough peer review

- No space constraints or color figure charges

- Immediate publication on acceptance

- Inclusion in PubMed, CAS, Scopus and Google Scholar

- Research which is freely available for redistribution

Submit your manuscript at www.biomedcentral.com/submit 